\title{
Boron-deficiency-responsive microRNAs and their targets in Citrus sinensis leaves
}

\author{
Yi-Bin Lu², Yi-Ping Qi ${ }^{3}$, Lin-Tong Yang ${ }^{1,2}$, Peng Guo ${ }^{1,2}$, Yan Li ${ }^{1}$ and Li-Song Chen ${ }^{1,2,4,5^{*}}$
}

\begin{abstract}
Background: MicroRNAs play important roles in the adaptive responses of plants to nutrient deficiencies. Most research, however, has focused on nitrogen $(\mathrm{N})$, phosphorus $(\mathrm{P})$, sulfur $(\mathrm{S})$, copper $(\mathrm{Cu})$ and iron $(\mathrm{Fe})$ deficiencies, limited data are available on the differential expression of miRNAs and their target genes in response to deficiencies of other nutrient elements. In this study, we identified the known and novel miRNAs as well as the boron (B)-deficiency-responsive miRNAs from citrus leaves in order to obtain the potential miRNAs related to the tolerance of citrus to B-deficiency.

Methods: Seedlings of 'Xuegan' [Citrus sinensis (L.) Osbeck] were supplied every other day with B-deficient ( $0 \mu \mathrm{M}$ $\mathrm{H}_{3} \mathrm{BO}_{3}$ ) or -sufficient $\left(10 \mu \mathrm{M} \mathrm{H}_{3} \mathrm{BO}_{3}\right.$ ) nutrient solution for 15 weeks. Thereafter, we sequenced two small RNA libraries from B-deficient and -sufficient (control) citrus leaves, respectively, using Illumina sequencing.

Results: Ninety one ( 83 known and 8 novel) up- and 81 (75 known and 6 novel) down-regulated miRNAs were isolated from B-deficient leaves. The great alteration of miRNA expression might contribute to the tolerance of citrus to B-deficiency. The adaptive responses of miRNAs to B-deficiency might related to several aspects: (a) attenuation of plant growth and development by repressing auxin signaling due to decreased TIR1 level and ARF-mediated gene expression by altering the expression of miR393, miR160 and miR3946; (b) maintaining leaf phenotype and enhancing the stress tolerance by up-regulating NACs targeted by miR159, miR782, miR3946 and miR7539; (c) activation of the stress responses and antioxidant system through down-regulating the expression of miR164, miR6260, miR5929, miR6214, miR3946 and miR3446; (d) decreasing the expression of major facilitator superfamily protein genes targeted by miR5037, thus lowering B export from plants. Also, B-deficiency-induced down-regulation of miR408 might play a role in plant tolerance to B-deficiency by regulating Cu homeostasis and enhancing superoxide dismutase activity.
\end{abstract}

Conclusions: Our study reveals some novel responses of citrus to B-deficiency, which increase our understanding of the adaptive mechanisms of citrus to B-deficiency at the miRNA (post-transcriptional) level.

Keywords: Boron-deficiency, Citrus sinensis, Illumina sequencing, Leaves, MicroRNA

\section{Background}

Boron (B), an essential micronutrient for normal growth and development of plants, is involved in a series of important physiological functions, including the structure of cell walls, membrane integrity, cell division, phenol metabolism, protein metabolism and nucleic acid metabolism during growth and development of higher plants [1-5]. B-deficiency widespreadly exists in many

\footnotetext{
* Correspondence: lisongchen2002@hotmail.com

${ }^{1}$ College of Resource and Environmental Science, Fujian Agriculture and Forestry University, Fuzhou 350002, China

${ }^{2}$ Institute of Horticultural Plant Physiology, Biochemistry and Molecular Biology, Fujian Agriculture and Forestry University, Fuzhou 350002, China Full list of author information is available at the end of the article
}

agricultural crops, including citrus. In China, B-deficiency is frequently observed in citrus orchards, and often contributes to the loss of productivity and poor fruit quality [3]. Li et al. reported that up to $9.0 \%$ and $43.5 \%$ of 'Guanximiyou' pummelo (Citrus grandis) orchards in Pinghe, Zhangzhou, China were deficient in leaf B and soil water-soluble B, respectively [6].

In plants, approx. 21-nucleotide-long microRNAs (miRNAs), one of the most abundant classes of non-coding small RNAs (sRNAs), are crucial post-transcriptional regulators of gene expression by repressing translation or directly degrading mRNAs in plants [7]. Evidence shows that miRNAs play key roles in plant response to nutrient 
deficiencies [8-13]. Identification of nutrient-deficiencyresponsive-miRNAs and their target genes has become one of the hottest topics in plant nutrition.

Plants have developed diverse strategies to maintain phosphorus $(\mathrm{P})$ homeostasis, including miRNA regulations $[11,12]$. MiR399, which is specifically induced by Pdeficiency in Arabidopsis and rice, can regulate $\mathrm{P}$ homeostasis by negatively regulating its target gene UBC24 [13, 14]. Like miR399, miR827 is also highly and specifically induced by P-deficiency and is involved in the regulation of plant $\mathrm{P}$ homeostasis by downregulating its target gene nitrogen limitation adaptation (NLA) in Arabidopsis [13]. In addition, many other Pdeficiency-responsive miRNAs (i.e., miR1510, miR156, miR159, miR166, miR169, miR2109, miR395, miR397, miR398, miR408, miR447 and miR482) have been isolated from various plant species [15-21].

MiR397, miR398, miR408, and miR857, which are induced by copper $(\mathrm{Cu})$-deficiency, have been shown to play a role in the regulation of $\mathrm{Cu}$ homeostasis by downregulating genes encoding nonessential $\mathrm{Cu}$ proteins such as $\mathrm{Cu} / \mathrm{Zn}$ superoxide dismutase (SOD), laccases and plantacyanin, hence saving $\mathrm{Cu}$ for other essential $\mathrm{Cu}$ proteins such as plastocyanin, which is essential for photosynthesis [10, 22, 23].

In Arabidopsis, leaf miR395 was induced by sulfur (S)deficiency. MiR395 targets ATP sulfurylases (APS) and sulfate transporter 2;1 (SULTR2;1), both of which are involved in the $\mathrm{S}$ metabolism. Their transcripts are greatly down-regulated in miR395-over-expressing transgenic Arabidopsis accompanied by increased accumulation of $\mathrm{S}$ in the shoot but not in the root. They concluded that miR395 play a role in the regulation of plant $\mathrm{S}$ accumulation and allocation by targeting APS and SULTR2;1 [24].

MiRNAs have been shown to play a role in the adaptation of plants to Fe-deficiency. Eight Fe-deficiencyresponsive conserved miRNAs from five families had been identified in Arabidopsis roots and shoots and their expression profiles differed between the two organs [25]. ValdésLópez et al. isolated ten up- and four down-regulated miRNAs, five up- and six down-regulated miRNAs, and seven up- and four down-regulated miRNAs from the leaves, roots and nodules of Fe-deficient common bean [17]. Waters et al. obtained eight differentially expressed miRNAs from seven conserved families in the rosettes of Fe-deficient Arabidopsis. Interestingly, Fe-deficiency led to increased accumulation of $\mathrm{Cu}$ in rosettes and decreased expression levels of miR397a, miR398a and miR398b/c, which regulate the mRNA levels of genes encoding $\mathrm{Cu}$ containing proteins, implying a links between Fedeficiency with $\mathrm{Cu}$ homeostasis [26].

Many N-deficiency-responsive miRNAs have been identified from Arabidopsis, soybean, maize and common bean. These miRNAs belong to at least 27 conserved families [10, 17, 27, 28]. In Arabidopsis, the expression of miR169 was inhibited by $\mathrm{N}$-deficiency, while the expression levels of its target genes [i.e., NFYA2 (Nuclear Factor $Y$, subunit A2), NFYA3, NFYA5 and NFYA8] were increased [10, 13, 27, 29]. Transgenic Arabidopsis plants over-expressing miR169a had less accumulation of $\mathrm{N}$ and NFYA family members, and were more sensitive to $\mathrm{N}$ stress than the wild type, demonstrating a role for miR169 in the adaptation of plants to N-deficiency [29]. It is worth noting that some N-deficiency-responsive miRNAs (e.g., miR169, miR172, miR394, miR395, miR397, miR398, miR399, miR827, miR408 and miR857) are also responsive to other nutrient stresses (i.e., B, P, Fe, $\mathrm{S}$ and $\mathrm{Cu}$ deficiencies) in plants $[8,10]$, indicating the involvement of miRNAmediated crosstalk among $\mathrm{N}, \mathrm{B}, \mathrm{P}, \mathrm{Fe}, \mathrm{S}$ and $\mathrm{Cu}$ under $\mathrm{N}$ deficiency.

An increasing number of nutrient-deficiency-responsive miRNAs have been identified with different techniques [8-14]. Most research, however, has focused on N, P, S, $\mathrm{Cu}$ and $\mathrm{Fe}$ deficiencies, limited data are available on the differential expression of miRNAs and their target genes in response to deficiencies of other nutrient elements. Recently, we investigated miRNA expression profiles in response to B-deficiency in Citrus sinensis roots by Illumina sequencing and identified 134 (112 known and 22 novel) B-deficiency-responsive miRNAs, suggesting the possible roles of miRNAs in the tolerance of citrus plants to B-deficiency [8]. Previous studies showed that the responses of miRNAs to nutrient deficiencies differed between plant roots and shoots (leaves) $[12,17,25]$. In addition, there were great differences in B-deficiencyinduced changes in major metabolites, activities of key enzymes involved in organic acid and amino acid metabolism, gas exchange and gene expression profiles between roots and leaves of $C$. sinensis $[4,30]$. Therefore, Bdeficiency-induced changes in miRNA expression profiles should be different between citrus roots and leaves.

In this study, we sequenced two small RNA libraries from B-deficient and -sufficient (control) citrus leaves, respectively, using Illumina sequencing, then identified the known and novel miRNAs as well as the B-deficiencyresponsive miRNAs. Also, we predicted the target genes of these known and novel B-deficiency-responsive miRNAs and discussed their possible roles in the response to B-deficiency in citrus. The objective of this study is to identify the potential miRNAs related to the tolerance of citrus to B-deficiency.

\section{Results}

\section{$B$ and $\mathrm{Cu}$ concentrations in leaves}

$\mathrm{B}$ concentration in $10 \mu \mathrm{M}$ B-treated leaves was in the sufficient range of 30 to $100 \mu \mathrm{g} \mathrm{g}^{-1} \mathrm{DW}$, while the value in $0 \mu \mathrm{M}$ B-treated leaves was much less than $30 \mu \mathrm{g} \mathrm{g}^{-1}$ DW (Fig. 1a) [31]. Visible B-deficient symptoms were 


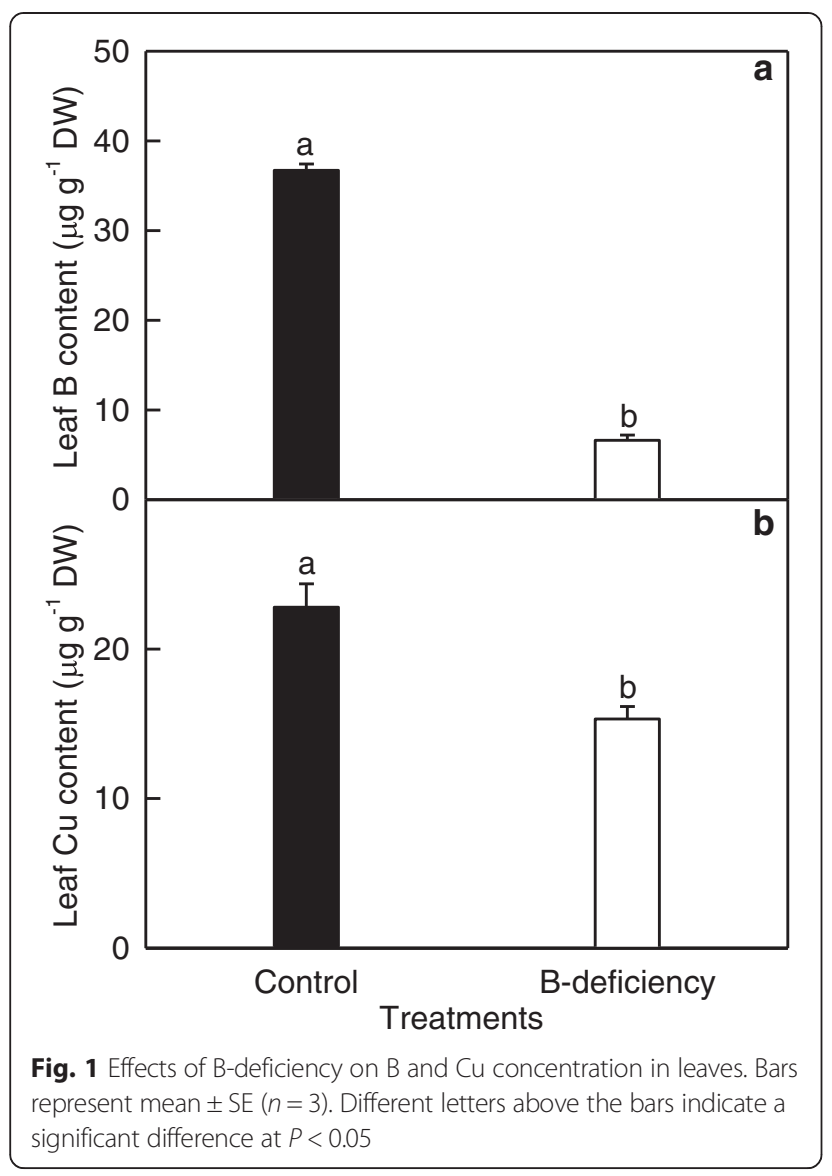

Fig. 1 Effects of B-deficiency on B and Cu concentration in leaves. Bars represent mean $\pm \mathrm{SE}(n=3)$. Different letters above the bars indicate a significant difference at $P<0.05$ observed only in $0 \mu \mathrm{M}$ B-treated leaves (data not shown). Therefore, seedlings treated with $0 \mu \mathrm{M} B$ are considered as B-deficient, and those treated with $10 \mu \mathrm{M}$ $\mathrm{B}$ are considered as B-sufficient. B-deficiency decreased leaf concentration of $\mathrm{Cu}$ (Fig. 1b).

\section{Sequencing and analysis of two small RNA libraries from B-sufficient and -deficient citrus leaves}

As shown in Table 1, 17,996,827 and 18,223,948 raw reads were generated from the libraries of B-sufficient and -deficient leaves, respectively. After removal of the contaminant reads like adaptors and low quality tags, $17,597,008$ and 17,829,966 clear reads were obtained from the libraries of B-sufficient and -deficient leaves, comprising 3,673,054 and 4,654,829 unique clear reads, respectively. Among these reads, 11,726,078 clean reads $(1,961,407$ unique reads) from B-sufficient leaves and $11,372,875$ clean reads $(2,484,833$ unique reads) from B-deficient leaves were mapped to $C$. sinensis genome (JGIversion 1.1, http://phytozome.jgi.doe.gov/ $\mathrm{pz} /$ portal.html\#! info?alias=Org_Csinensis) using SOAP [32]. Exon, intron, miRNA, rRNA, repeat regions, snRNA, snoRNA and tRNA reads were annotated, respectively. After removal of these annotated reads, the remained unique reads that were used to predict novel miRNAs for B-sufficient and -deficient leaves were $3,237,407$ and 4,179,224 reads, respectively.

Most of the clear sequences were within the range of 19-26 nt, which accounted for $89 \%$ of the total clear reads. Reads with the length of 24 nt were at the most abundant, followed by the reads with the length of 21,22 , 23 and 20 nt (Additional file 1). Overall, the size distribution of sRNAs agrees with the results obtained on roots of

Table 1 Statistical analysis of sRNA sequencing data from B-sufficient and-deficient leaves of Citrus sinensis

\begin{tabular}{lllll}
\hline & \multicolumn{2}{l}{ B-sufficiency } & \multicolumn{2}{l}{ B-deficiency } \\
\cline { 2 - 3 } & Unique sRNAs & Total sRNAs & Unique sRNAs & Total sRNAs \\
\hline Raw reads & & $17,996,827$ & $18,223,948$ \\
Clear reads & $3,673,054(100 \%)$ & $17,597,008(100 \%)$ & $4,654,829(100 \%)$ & $17,829,966(100 \%)$ \\
Mapped to genomic & $1,961,407(53.40 \%)$ & $11,726,078(66.64 \%)$ & $2,484,833(53.38 \%)$ & $11,372,875(63.79 \%)$ \\
Exon antisense & $28,626(0.78 \%)$ & $134,009(0.76 \%)$ & $42,754(0.92 \%)$ & $157,929(0.89 \%)$ \\
Exon sense & $77,868(2.12 \%)$ & $281,505(1.60 \%)$ & $81,887(1.76 \%)$ & $287,483(1.61 \%)$ \\
Intron antisense & $36,541(0.99 \%)$ & $244,148(1.39 \%)$ & $46,940(1.01 \%)$ & $248,094(1.39 \%)$ \\
Intron sense & $56,020(1.53 \%)$ & $526,848(2.99 \%)$ & $67,594(1.45 \%)$ & $457,839(2.57 \%)$ \\
miRNA & $44,496(1.21 \%)$ & $3,858,007(21.92 \%)$ & $46,800(1.01 \%)$ & $2,639,999(14.81 \%)$ \\
rRNA & $164,311(4.47 \%)$ & $3,052,914(17.35 \%)$ & $158,009(3.39 \%)$ & $2,851,216(15.99 \%)$ \\
repeat & $821(0.02 \%)$ & $2009(0.01 \%)$ & $1014(0.02 \%)$ & $2718(0.02 \%)$ \\
snRNA & $2420(0.07 \%)$ & $8040(0.05 \%)$ & $3547(0.08 \%)$ & $10,269(0.06 \%)$ \\
snoRNA & $1167(0.03 \%)$ & $3628(0.02 \%)$ & $1270(0.03 \%)$ & $4748(0.03 \%)$ \\
tRNA & $23,377(0.64 \%)$ & $810,902(4.61 \%)$ & $25,790(0.55 \%)$ & $722,780(4.05 \%)$ \\
Unannotated sRNAs & $3,237,407(88.14 \%)$ & $8,674,998(49.30 \%)$ & $4,179,224(89.78 \%)$ & $10,446,891(58.59 \%)$ \\
\hline
\end{tabular}


Citrus sinensis [8], fruits of C. sinensis [33] and Citrus trifoliata, and flowers of C. trifoliate [34]. This indicates that the data of sRNA libraries obtained by the Illumina sequencing are reliable.

Identification of known and novel miRNAs in citrus leaves Here, a total of 734 known miRNAs were isolated from the two libraries (Additional file 2). The count of reads was normalized to transcript per million (TPM) in order to compare the abundance of miRNAs in the two libraries. The most abundant miRNA isolated from B-sufficient and -deficient libraries was miR157 (86,829.4201 and 48,091.4546 TPM, respectively), followed by miR166 (36,979.7525 and 26148.2271 TPM, respectively) and miR167 (24,944.5815 and 16,269.745, respectively). In this study, only these known miRNAs with normalized read-count more than ten TPM in B-sufficient and/or -deficient leaf libraries were used for further analysis in order to avoid false results caused by the use of low expressed miRNAs [8, 35]. After removal of these low expressed miRNAs, the remained 321 known miRNAs were used for further analysis (Additional file 3).

After removal of these annotated reads (i.e., exon, intron, miRNA, rRNA, repeat regions, snRNA, snoRNA and tRNA), the remained 3,237,407 and 4,179,224 reads from B-sufficient and -deficient libraries, respectively were used to predict novel miRNAs using the Mireap (http://sourceforge.net/projects/mireap/). Based on the criteria for annotation of plant miRNAs [7, 36], a total of 71 novel miRNAs were isolated from the two libraries (Additional file 4). Like the known miRNAs, novel miRNAs with normalized read-count less than ten TPM were not included in the expression analysis [7, 35]. After excluding these low expressed novel miRNAs, the remained 28 miRNAs were used for further analysis (Additional file 5).

\section{Identification of B-deficiency-responsive miRNAs in citrus leaves}

We identified 91 ( 83 known and 8 novel) up- and 81 (75 known and 6 novel) down-regulated miRNAs from B-deficient leaves. The most pronounced up- and downregulated known (novel) miRNAs were miR5266 with a fold-change of 16.22 (novel_miR_95 with a fold-change of 17.61) and miR401 with a fold-change of -15.87 (novel_miR_236 with a fold-change of -18.48), respectively (Additional files 3 and 5).

\section{Validation of high-throughput sequencing results by qRT- PCR}

We analyzed the expression of 27 known miRNAs using stem-loop qRT-PCR in order to validate the miRNA expression patterns revealed by Illumina sequencing. The expression levels of all these miRNAs except for miR6214,
miR5262 and miR7841 were comparable in magnitude to the expression patterns obtained by Illumiona sequencing (Fig. 2). Obviously, the high-throughput sequencing allowed us to identify the differentially expressed miRNAs under Bdeficiency.

\section{Identification of targets for differentially expressed miRNAs and GO analysis}

In this study, we predicted 489 and 17 target genes from the 70 known and 6 novel differentially expressed miRNAs, respectively (Additional files 6 and 7). GO categories were assigned to all these target genes based on the cellular component, molecular function and biological process. These target genes for the known and novel miRNAs were related to 12 and 3 components, respectively based on the cellular component. The most three GO terms for known miRNAs were membrane, chloroplast and plastid, while more than $42 \%$ of the target genes for novel miRNAs belonged to membrane (Fig. 3a). Based on the molecular function, the target genes for the known and novel miRNAs genes were grouped into 11 and 9 categories, respectively, the highest percentage of three categories were nucleic acid binding, metal ion binding and transcription factor activity (Fig. 3b). In the biological process, the target genes were mainly focused on response to stress and developmental process for known miRNAs, and nucleic acid metabolic process, developmental process, response to stress and regulation of transcription for novel miRNAs, respectively (Fig. 3c).

\section{qRT-PCR validation of target genes}

To verify the expression of the target genes and how the miRNAs regulate their target genes, 77 genes targeted by 14 down- and 13 up-regulated miRNAs were assayed by qRT-PCR (Table 2). Among the 77 genes, the expression changes of 58 target genes showed a negative correlation with their corresponding miRNAs, implying that miRNAs might play a role in regulating gene expression under B-deficiency by cleaving mRNAs. However, the expression changes of the remained 19 target genes had a positive correlation with their corresponding miRNAs, which might be the results of the interaction of different target genes.

\section{Discussion}

Evidence shows that miRNAs are involved in the adaptive regulation of higher plants to nutrient deficiencies $[8,13,17,19,24,27,37]$. Here, we isolated 91 (83 known and 8 novel) up- and 81 (75 known and 6 novel) downregulated miRNAs from B-deficient leaves (Additional files 3 and 5), indicating that B-deficiency greatly affected the expression profiles of miRNAs in leaves. The differentially expressed miRNAs isolated from leaves were more than from roots [i.e., 52 (40 known and 12 novel) up- and 82 (72 

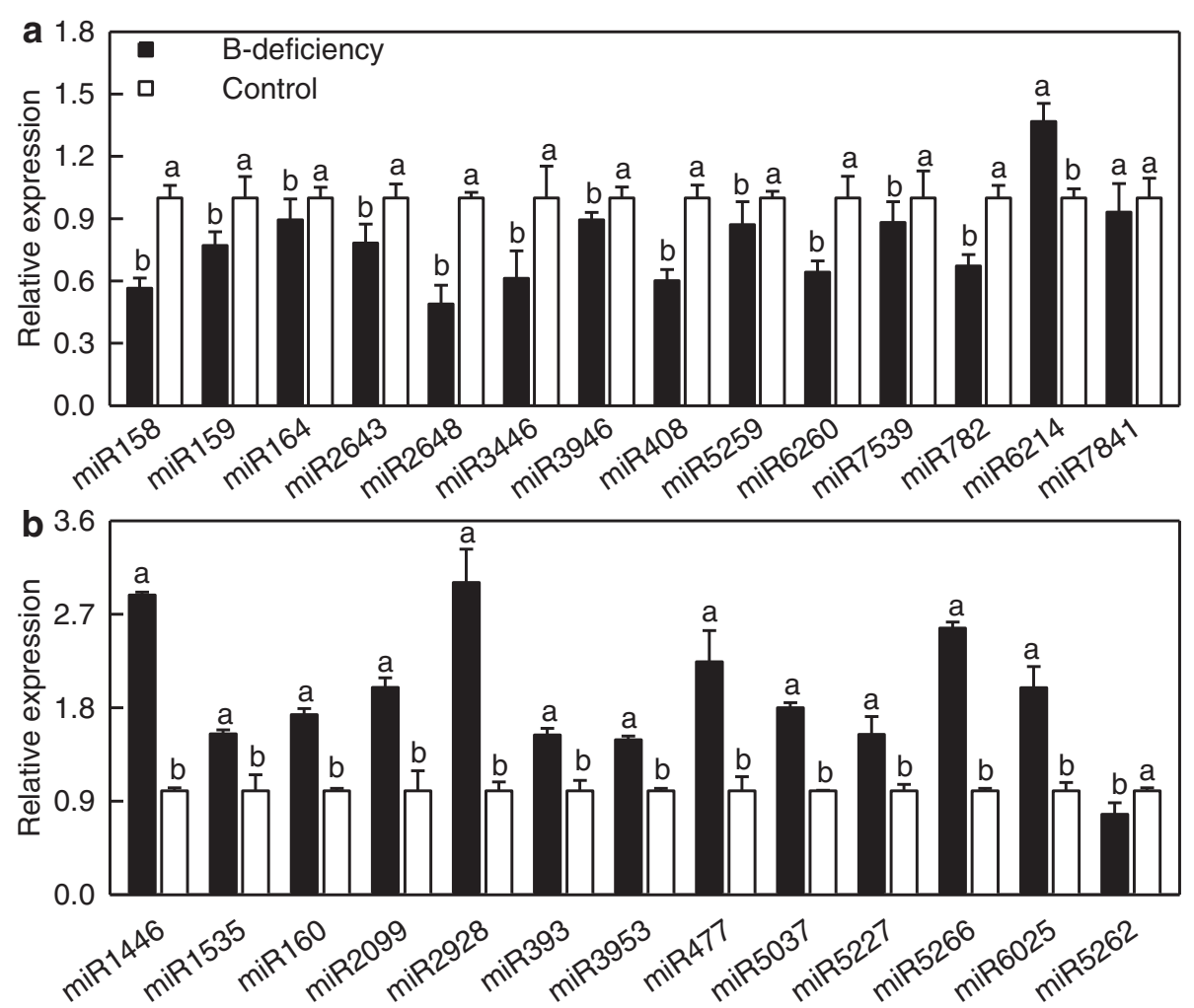

Fig. 2 Relative abundances of selected known miRNAs in B-deficient and control leaves revealed by qRT-PCR. Bars represent mean \pm SD $(n=3)$. Significant differences were tested between control and B-deficient leaves for the same miRNA. Different letters above the bars indicate a significant difference at $P<0.05$. All the values were expressed relative to the control leaves

known and 10 novel) down-regulated miRNAs] [8]. The majority of the differentially expressed miRNAs were isolated only from B-deficient roots or leaves, only 22 miRNAs were isolated from the both. Moreover, among the $22 \mathrm{miR}$ NAs, 11 miRNAs in roots and leaves displayed different responses to B-deficiency (Table 3). In conclusion, many differences existed in B-deficiency-induced changes in miRNA expression profiles between roots and leaves.

We found that miR159 was down-regulated in Bdeficient leaves (Table 2), as previously obtained on salt stressed sugarcane leaves [38]. Patade and Suprasanna showed that the up-regulation of $M Y B$ at $1 \mathrm{~h}$ of saltstressed sugarcane leaves was accompanied by the down-regulation of miR159 [38]. However, the expression of miR159 was up-regulated in P-deficient soybean (Glycine $\max$ ) roots and leaves [39]. MiR159 plays important roles in maintaining leaf phenotype by negatively regulating MYB transcription factors [40]. Dai et al. reported that the expression of OsMYB3R-2 was induced by various abiotic stresses, and that over-expression of OsMYB3R-2 enhanced tolerance to freezing, drought, and salt stress in transgenic Arabidopsis [41]. B-1deficiency affects water uptake into the root, transport through the shoot, and loss of water from the leaves [42]. Thus, Bdeficiency-induced down-regulation of miR159 might increase the expression of MYBs (Table 2), thus improving the tolerance of plants to B-deficiency. qRT-PCR showed that all the four $M Y B s$ target genes (i.e., $M Y B$ domain protein 33, MYB domain protein 97, MYB-like HTH transcriptional regulator family protein and $M Y B$ domain protein 65) were induced by B-deficiency except for the last one. Similarly, the expression levels of MYB transcription factor (MYBML2) targeted by miR782, MYB-like HTH transcriptional regulator family protein and $M Y B$ domain protein 65 targeted by miR3946, and MYB-like HTH transcriptional regulator family protein and MYB transcription factor (MYBML2) targeted by miR7539 increased in response to B-deficiency except for MYB domain protein 65 (Table 2). B-deficiency-induced up-regulation of MYBs in citrus leaves agrees with the previous report that the expression of MYB85, MYB63 and MYB42 were upregulated at the slight corking veins and the seriously corky split veins caused by B-deficiency in 'Newhall' navel orange (Citrus sinensis) leaves [43].

TIR1/AFB2 (TRANSPORT INHIBITOR RESPONSE1/ AUXIN SIGNALING F-BOX PROTEIN2) Auxin Receptor (TAAR) family F-box proteins are involved in auxin perception and signaling. The expression of TAAR is regulated by miR393 [44]. MiR393 plays a key role in maintaining proper homeostasis of auxin signaling [45]. 

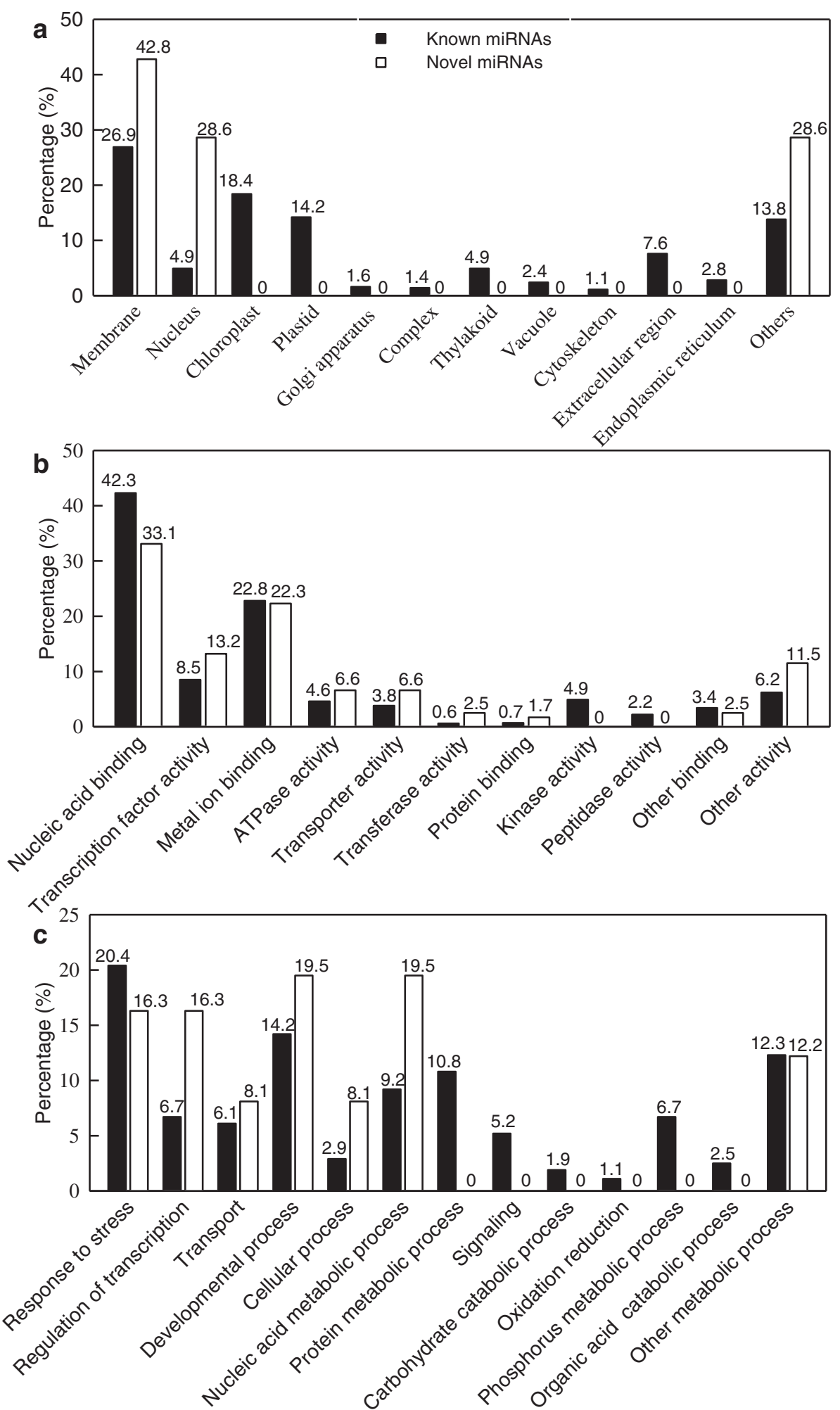

Fig. $3 \mathrm{GO}$ of the predicted target genes for 70 (6) differentially expressed known (novel) miRNAs. Categorization of miRNAs target genes was performed according to cellular component (a), molecular function (b) and biological process (c) 
Table 2 qRT-PCR relative expression of experimentally determined or predicted target genes of selected miRNAs

\begin{tabular}{|c|c|c|c|c|c|}
\hline miRNA & $\begin{array}{l}\text { Fold change of } \\
\text { miRNA }\end{array}$ & Accession & Homology & Target genes & $\begin{array}{l}\text { Relative change of } \\
\text { target genes }\end{array}$ \\
\hline \multirow[t]{3}{*}{ miR158 } & $-3.35603222^{* *}$ & orange $1.1 \mathrm{~g} 022993 \mathrm{~m}$ & AT1G69840.1 & $\begin{array}{l}\text { SPFH/Band 7/PHB domain-containing } \\
\text { membrane-associated protein family }\end{array}$ & $1.9490^{* *}$ \\
\hline & & & AT2G03210 & Fucosyltransferase 2 & $1.6482^{* *}$ \\
\hline & & orange1.1g001709m & AT3G07400 & Lipase class 3 family protein & $0.7819^{*}$ \\
\hline \multirow[t]{5}{*}{ miR159 } & $-2.04145817^{* *}$ & orange1.1g039708m & AT5G06100.2 & MYB domain protein 33 & $1.1319^{*}$ \\
\hline & & orange1.1g044979m & AT4G27330.1 & Sporocyteless (SPL) & $2.2016^{* *}$ \\
\hline & & orange1.1g046419m & AT4G26930.1 & MYB domain protein 97 & $1.9078^{* *}$ \\
\hline & & orange1.1g011938m & AT3G11440.1 & MYB domain protein 65 & $0.8778^{* *}$ \\
\hline & & orange $1.1 \mathrm{~g} 038795 \mathrm{~m}$ & АT3G60460.1 & $\begin{array}{l}\text { MYB-like HTH transcriptional regulator } \\
\text { family protein }\end{array}$ & $1.6685^{* *}$ \\
\hline \multirow[t]{3}{*}{ miR160 } & $1.81653886^{* *}$ & orange1.1g004896m & AT2G28350.1 & ARF10 & $0.7870^{* *}$ \\
\hline & & orange1.1g005075m & AT4G30080.1 & ARF16 & $0.7150^{* *}$ \\
\hline & & orange1.1g008078m & AT1G77850.1 & ARF17 & $0.9153^{* *}$ \\
\hline \multirow[t]{4}{*}{ miR164 } & $-2.28320824^{* *}$ & orange1.1g030909m & AT1G56010.2 & NAC domain containing protein 1 & $0.5939^{* *}$ \\
\hline & & orange1.1g047710m & AT5G53950.1 & $\begin{array}{l}\text { NAC domain transcriptional regulator superfamily } \\
\text { protein }\end{array}$ & $1.4205^{* *}$ \\
\hline & & orange1.1g017827m & AT5G61430.1 & NAC domain containing protein 100 & $1.3247^{* *}$ \\
\hline & & orange1.1g017636m & AT3G08030.1 & Protein of unknown function, DUF642 & $0.5400^{* *}$ \\
\hline \multirow[t]{3}{*}{ miR158 } & $-3.35603222^{* *}$ & orange $1.1 \mathrm{~g} 022993 \mathrm{~m}$ & AT1G69840.1 & $\begin{array}{l}\text { SPFH/Band 7/PHB domain-containing } \\
\text { membrane-associated protein family }\end{array}$ & $1.9490^{* *}$ \\
\hline & & & AT2G03210 & Fucosyltransferase 2 & $1.6482^{* *}$ \\
\hline & & orange1.1g001709m & AT3G07400 & Lipase class 3 family protein & $0.7819^{*}$ \\
\hline \multirow[t]{5}{*}{ miR393 } & $1.66802767^{* *}$ & orange1.1g010049m & AT3G18080.1 & B-S glucosidase 44 & $0.8384^{* *}$ \\
\hline & & orange1.1g007916m & At3g62980 & TIR1 & $0.7489^{* *}$ \\
\hline & & & At4g03190 & AFB1 & $0.8195^{* *}$ \\
\hline & & orange1.1g008325m & At3g26810 & AFB2 & $0.7895^{* *}$ \\
\hline & & & At1g12820 & AFB3 & $1.6782^{* *}$ \\
\hline \multirow[t]{4}{*}{ miR408 } & $-2.55840249 * *$ & orange1.1g013075m & At2g30210 & Laccase 3 & $1.5874^{* *}$ \\
\hline & & orange1.1g041358m & At5g05390 & Laccase 12 & $0.8814^{* *}$ \\
\hline & & & At5g07130 & Laccase 13 & $1.1251^{*}$ \\
\hline & & orange1.1g048131m & At2g02850 & Plantacyanin & $1.6723^{* *}$ \\
\hline miR477 & $3.82198862^{* *}$ & orange1.1g018483m & AT3G11340.1 & UDP-Glycosyltransferase superfamily protein & $0.6543^{* *}$ \\
\hline \multirow[t]{2}{*}{ miR782 } & $-10.08402439 * *$ & & HQ202267 & MYB transcription factor (MYBML2) & $1.5782^{* *}$ \\
\hline & & orange1.1g039969m & NM_001112290 & Protein disulfide isomerase (PDIL5-1) & $0.9081^{* *}$ \\
\hline miR1446 & $5.01671689^{* *}$ & orange1.1g037028m & AT1G14920.1 & GRAS family transcription factor family protein & $0.7887^{* *}$ \\
\hline \multirow[t]{2}{*}{ miR1535 } & $1.58529156^{* *}$ & orange1.1g001616m & AT3G63380.1 & $\begin{array}{l}\text { ATPase E1-E2 type family protein/haloacid } \\
\text { dehalogenase-like hydrolase family protein }\end{array}$ & $0.6757^{* *}$ \\
\hline & & orange1.1g015157m & AT3G58060.1 & Cation efflux family protein & $0.7189^{* *}$ \\
\hline miR2099 & $10.31417531^{* *}$ & orange1.1g017694m & AT3G22830.1 & Heat shock transcription factor A6B & $0.6459^{* *}$ \\
\hline \multirow[t]{2}{*}{$\operatorname{miR} 2643$} & $-2.52218131^{* *}$ & orange1.1g018307m & AT1G12500.1 & Nucleotide-sugar transporter family protein & 0.9924 \\
\hline & & orange1.1g020050m & AT5G19890.1 & Peroxidase superfamily protein & $1.2307^{* *}$ \\
\hline miR2648 & $-11.76162602^{* *}$ & orange1.1g003798m & AT5G58460.1 & Cation $/ \mathrm{H}^{+}$exchanger 25 & $2.0379^{* *}$ \\
\hline \multirow[t]{3}{*}{$\operatorname{miR} 2928$} & $13.58236255^{* *}$ & orange1.1g007099m & AT4G04450.1 & WRKY family transcription factor & $0.4129^{* *}$ \\
\hline & & orange1.1g014735m & AT4G22070.1 & WRKY DNA-binding protein 31 & $1.4500^{* *}$ \\
\hline & & orange1.1g016623m & AT1G62300.1 & WRKY family transcription factor & $0.5791^{* *}$ \\
\hline
\end{tabular}


Table 2 qRT-PCR relative expression of experimentally determined or predicted target genes of selected miRNAs (Continued)

\begin{tabular}{|c|c|c|c|c|c|}
\hline \multirow[t]{3}{*}{ miR3446 } & $-1.83050087^{* *}$ & orange1.1g004633m & AT5G66850.1 & Mitogen-activated protein kinase kinase kinase 5 & $1.6310^{*}$ \\
\hline & & orange1.1g004928m & AT2G25930.1 & Hydroxyproline-rich glycoprotein family protein & $1.3981^{* *}$ \\
\hline & & orange $1.1 \mathrm{~g} 036074 \mathrm{~m}$ & AT4G22200.1 & Potassium transport $2 / 3$ & $1.2999^{* *}$ \\
\hline \multirow[t]{17}{*}{ miR3946 } & $-1.66667782^{* *}$ & orange1.1g029573m & AT5G47370.1 & Homeobox-leucine zipper protein 4 (HB-4)/HD-ZIP protein & $0.7342^{*}$ \\
\hline & & orange1.1g041705m & AT4G25980.1 & Peroxidase superfamily protein & $1.5621^{* *}$ \\
\hline & & orange $1.1 \mathrm{~g} 031837 \mathrm{~m}$ & AT1G08830.1 & Copper/zinc superoxide dismutase 1 & $1.6638^{* *}$ \\
\hline & & orange1.1g016997m & AT1G13310.1 & Endosomal targeting BRO1-like domain-containing protein & $0.5406^{* *}$ \\
\hline & & orange1.1g014089m & AT1G73390.1 & $\begin{array}{l}\text { Endosomal targeting BRO1-like domain-containing } \\
\text { protein }\end{array}$ & $1.3404^{* *}$ \\
\hline & & orange $1.1 \mathrm{~g} 027084 \mathrm{~m}$ & AT3G20560.1 & PDI-like 5-3 & $1.0827^{*}$ \\
\hline & & orange $1.1 \mathrm{~g} 017665 \mathrm{~m}$ & AT3G04070.1 & NAC domain containing protein 47 & $1.6886^{* *}$ \\
\hline & & orange1.1g010076m & AT3G54700.1 & Phosphate transporter $1 ; 7$ & $1.7862^{* *}$ \\
\hline & & orange1.1g034408m & AT1G33110.1 & MATE efflux family protein & $1.5697^{* *}$ \\
\hline & & orange $1.1 \mathrm{~g} 027612 \mathrm{~m}$ & AT1G04760.1 & Vesicle-associated membrane protein 726 & $1.2270^{* *}$ \\
\hline & & orange1.1g027026m & AT4G27670.1 & Heat shock protein 21 & $1.3134^{* *}$ \\
\hline & & orange1.1g020124m & AT2G01060.1 & MYB-like HTH transcriptional regulator family protein & $1.7116^{* *}$ \\
\hline & & orange1.1g011938m & AT3G11440.1 & MYB domain protein 65 & $0.8396^{* *}$ \\
\hline & & orange1.1g005651m & AT1G32640.1 & $\begin{array}{l}\text { Basic helix-loop-helix (bHLH) DNA-binding family } \\
\text { protein }\end{array}$ & $1.3806^{* *}$ \\
\hline & & orange $1.1 \mathrm{~g} 012387 \mathrm{~m}$ & AT4G00050.1 & $\begin{array}{l}\text { Basic helix-loop-helix (bHLH) DNA-binding superfam- } \\
\text { ily protein }\end{array}$ & $1.6480^{* *}$ \\
\hline & & orange1.1g004509m & AT2G45290.1 & Transketolase & $1.1778^{*}$ \\
\hline & & orange1.1g033760m & AT2G46690.1 & SAUR-like auxin-responsive protein family & $0.7430^{* *}$ \\
\hline \multirow[t]{2}{*}{ miR3953 } & $3.80237602^{* *}$ & orange1.1g016435m & AT5G46590.1 & NAC domain containing protein 96 & $0.7783^{* *}$ \\
\hline & & orange1.1g017142m & AT5G22290.1 & NAC domain containing protein 89 & $1.1842^{*}$ \\
\hline \multirow[t]{2}{*}{ miR5037 } & $10.12893993^{* *}$ & orange1.1g013411m & AT2G16980.2 & Major facilitator superfamily protein & $0.5828^{* *}$ \\
\hline & & orange1.1g016066m & AT2G16990.2 & Major facilitator superfamily protein & $0.4849^{* *}$ \\
\hline \multirow[t]{2}{*}{$\operatorname{miR5227}$} & $1.8059848^{* *}$ & orange1.1g031467m & AT2G24860.1 & DnaJ/Hsp40 cysteine-rich domain superfamily protein & $0.4641^{* *}$ \\
\hline & & orange1.1g018585m & AT1G31260.1 & Zinc transporter 10 precursor & $1.2609^{* *}$ \\
\hline \multirow[t]{2}{*}{ miR5262 } & $1.64808069^{* *}$ & orange1.1g005832m & AT1G06820.1 & Carotenoid isomerase & $1.5524^{* *}$ \\
\hline & & orange $1.1 \mathrm{~g} 003885 \mathrm{~m}$ & AT5G49890.1 & Chloride channel C & $0.844^{* *}$ \\
\hline miR5266 & $16.22392231^{* *}$ & orange1.1g040022m & AT4G13510.1 & Ammonium transporter $1 ; 1$ & $1.2439^{*}$ \\
\hline miR5929 & $-5.83479907^{* *}$ & orange1.1g005910m & AT5G42480.1 & Chaperone DnaJ-domain superfamily protein & $1.3663^{* *}$ \\
\hline \multirow[t]{2}{*}{ miR6025 } & $3.39080972^{* *}$ & orange1.1g005832m & AT1G06820.1 & Carotenoid isomerase & 0.6716 \\
\hline & & orange1.1g023118m & AT2G21940.4 & Shikimate kinase 1 & $0.7012^{* *}$ \\
\hline miR6214 & $-3.978202^{* *}$ & orange1.1g037661m & AT5G37380.4 & Chaperone DnaJ-domain superfamily protein & $1.2352^{* *}$ \\
\hline \multirow[t]{4}{*}{ miR6260 } & $-6.8442483^{* *}$ & orange1.1g010903m & AT5G15130.1 & WRKY DNA-binding protein 72 & $3.2313^{* *}$ \\
\hline & & orange1.1g003752m & AT5G42480.1 & Chaperone DnaJ-domain superfamily protein & $1.3327^{* *}$ \\
\hline & & orange1.1g041599m & AT1G49330.1 & Hydroxyproline-rich glycoprotein family protein & $0.9023^{* *}$ \\
\hline & & orange $1.1 \mathrm{~g} 029026 \mathrm{~m}$ & AT1G64650.1 & Major facilitator superfamily protein & $1.777^{* *}$ \\
\hline \multirow[t]{2}{*}{$\operatorname{miR7539}$} & $-4.033976^{* *}$ & orange1.1g002698m & AT2G42600.1 & Phosphoenolpyruvate carboxylase 2 & $1.5943^{* *}$ \\
\hline & & orange $1.1 \mathrm{~g} 020124 \mathrm{~m}$ & AT2G01060.1 & MYB-like HTH transcriptional regulator family protein & $1.1878^{* *}$ \\
\hline $\operatorname{miR7841}$ & $-10.61512382^{* *}$ & orange1.1g041450m & AT3G42640.1 & $\mathrm{H}^{+}$-ATPase 8 & $0.8903^{* *}$ \\
\hline
\end{tabular}

Both fold change of miRNAs and relative change of target genes are the ratio of B-deficient to -sufficient leaves. The value is an average of at least three biological replicates with three technical replicates; Target genes that had the expected changes in mRNA levels were marked in bold. * and ** indicate a significant difference at $P<0.05$ and $P<0.01$, respectively 
Table 3 List of differentially expressed miRNAs present in both roots and leaves

\begin{tabular}{|c|c|c|}
\hline \multirow[t]{2}{*}{ MiRNA } & \multicolumn{2}{|l|}{ Fold change } \\
\hline & Roots & Leaves \\
\hline miR418 & $1.87710209^{* *}$ & $2.01596507^{* *}$ \\
\hline miR4413 & $3.76410603^{* *}$ & $-5.94405631^{* *}$ \\
\hline miR5037 & $4.79286276^{* *}$ & $10.12893993^{* *}$ \\
\hline miR3946 & $5.08067752^{* *}$ & $-1.66667782^{* *}$ \\
\hline miR5259 & $6.34492626^{* *}$ & $-5.83479907^{* *}$ \\
\hline miR2099 & $13.49283335^{* *}$ & $10.31417531^{* *}$ \\
\hline miR2622 & $13.96750818^{* *}$ & $10.13868134^{* *}$ \\
\hline miR2664 & $14.36084091^{* *}$ & $-13.05830635^{* *}$ \\
\hline miR5266 & $-1.5614939^{* *}$ & $16.22392231^{* *}$ \\
\hline miR394 & $-5.15694535^{* *}$ & $-1.66667782^{* *}$ \\
\hline miR3513 & $-5.84396568^{* *}$ & $-7.04650639^{* *}$ \\
\hline miR5492 & $-6.7798681^{* *}$ & $-5.48597088^{* *}$ \\
\hline miR5534 & $-7.1665574^{* *}$ & $-2.89672418^{* *}$ \\
\hline miR5029 & $-7.43642552^{* *}$ & $6.19590225^{* *}$ \\
\hline miR5211 & $-8.31439018^{* *}$ & $14.53849221^{* *}$ \\
\hline miR1847 & $-9.0000212^{* *}$ & $10.94295432^{* *}$ \\
\hline miR158 & $-10.05808647^{* *}$ & $-3.35603222^{* *}$ \\
\hline miR2921 & $-10.13114959^{* *}$ & $-11.0611889^{* *}$ \\
\hline miR782 & $-10.76475548^{* *}$ & $-10.08402439^{* *}$ \\
\hline miR1446 & $-10.94721705^{* *}$ & $5.01671689 * *$ \\
\hline miR5074 & $-10.94721705^{* *}$ & $10.74971862^{* *}$ \\
\hline miR3443 & $-11.47199392^{* *}$ & $9.96792062^{* *}$ \\
\hline
\end{tabular}

Si-Ammour et al. showed that miR393 down-regulated all four TAAR genes by guiding the cleavage of their mRNAs, leading to the changes in auxin perception and some auxin-related leaf development [44]. Stress-induced increase in miR393 level may decrease the level of TIR1, a positive regulator of growth and development, thereby resulting in attenuation in growth and development during stress conditions [14]. Auxin response factors (ARFs) play a role in relaying auxin signaling at the transcriptional level by inducing mainly three groups of genes [i.e., Aux/IAA (Auxin/indole-3-acetic acid), GH3 and small auxin-up RNA (SAUR)] [46, 47]. MiR160 is predicted to target ARF10, ARF16 and ARF17. MiR160-directed regulation of Arabidopsis ARF17 is necessary for the normal growth and development of many organs, proper GH3-like gene expression and perhaps auxin distribution, while the ARF10 and ARF16 knockout mutants do not display obvious developmental anomalies [48]. Weakened plant growth and reduced metabolic rate are common survival strategies employed to divert energy and other resources to deal with stress conditions. It has been suggested that the stress- induced up-regulation of miR393 and miR160 might lead to the attenuation of plant growth and development under stress by repressing auxin signaling due to decreased TIR1 level and by suppressing the ARF-mediated gene expression, respectively, thus promoting plant stress tolerance [47]. Therefore, B-deficiency-induced up-regulation of leaf miR393 and miR160 might be an adaptive response of plants to B-deficiency, because the expression of the three genes targeted by miR160 and TIR1, $A F B 1, A F B 2$ and $A F B 3$ targeted by miR393 was downregulated by B-deficiency except for AFB3 (Table 2). Similarly, the expression of SAUR-like auxin-responsive protein family targeted by miR3946 was down-regulated in B-deficient leaves despite decreased expression of miR3946 (Table 2). By contrast, root miR3946 was up-regulated by B-deficiency [8].

Leaf miR164 was down-regulated by B-deficiency (Table 2), as previously observed on transient low nitratestressed maize leaves [28]. Water stress led to decreased expression of miR164 in cassava (Manihot esculenta) leaves, while its target gene MesNAC (No Apical Meristem) was strongly induced [49]. As expected, the expression of NAC domain transcriptional regulator superfamily protein and NAC domain containing protein 100 was induced in B-deficient leaves, while the expression of NAC domain containing protein 1 was depressed (Table 2). Over-expression of SNAC1 and OsNAC6 conferred drought and salt tolerance in rice [50, 51]. SINAC4-RNAi tomato plants became less tolerant to salt and drought stress [52]. Therefore, the down-regulation of miR164 in B-deficient leaves might be involved in the B-deficiency tolerance of plants by improving the expression of NAC. However, Xu et al. found that miR164 was up-regulated in maize leaves under chronic $\mathrm{N}$ limitation, and suggested that miR164 might function in remobilizing the $\mathrm{N}$ from old to new leaves to cope with the $\mathrm{N}$-limiting condition via accelerating senescence due to decreased expression of NAC [28].

Leaf miR408 was down-regulated by B-deficiency (Table 2), as previously reported on $\mathrm{N}$-deficient seedlings of Arabidopsis [27]. MiR408 targets genes encoding $\mathrm{Cu}$ containing proteins such as $\mathrm{Cu} / \mathrm{Zn}$ SODs (CSDs), plantacyanin and several laccases [23]. Abdel-Ghany and Pilon observed that miR408 was induced under $\mathrm{Cu}$ starvation to down-regulate target gene expression and to save $\mathrm{Cu}$ for the most essential functional protein, concluding that might play a role in the regulation of $\mathrm{Cu}$ homeostasis [22]. Although B-deficiency decreased leaf concentration of $\mathrm{Cu}$, its level was not lower than the sufficiency range of $\mathrm{Cu}$ in citrus leaves [53]. Thus, B-deficiency-induced decrease in miR408 might be advantageous to plant survival under B-deficiency by regulating $\mathrm{Cu}$ homeostasis and improving antioxidant (SOD) activity, because the expression of its four target genes was induced by B-deficiency 
except for laccase 12 (Table 2). Indeed, SOD activity was higher in B-deficient $C$. sinensis leaves than in B-sufficient ones [54]. Also, SOD expression was up-regulated in Bdeficient Medicago truncatula root nodules [55].

Leaf $m i R 477$ was up-regulated by B-deficiency (Table 2), as previously reported on salt-stressed Populus cathayana plantlets [56]. NAC and GRAS transcription factors are target genes of miR477. NAC is involved in developmental process and stress responses [56], while GRAS proteins play a role in signal transduction and the maintenance and development of meristems [57]. Also, GRAS is the target gene of miR1446 (Table 2), miR170 and miR171 [58], and $N A C$ is the target gene of miR164, miR3953 and miR3946 (Table 2). This indicates the complex regulation in plant development and stress response.

WRKY proteins play important roles in plant responses to (a)biotic stresses, allowing plants to adapt to unfavorable environmental conditions including B-deficiency [59, 60]. Our results showed that leaf transcript of miR6260 decreased in response to B-deficiency accompanied by increased expression of its target gene: WRKY DNA-binding protein 72 (Table 2), which agrees with the previous reports that WRKY3 DNA binding protein expression was induced in B-deficient $M$. truncatula root nodules [55] and that WRKY6 was up-regulated in B-deficient Arabidopsis roots [60]. Over-expression of various WRKY conferred tolerance to different abiotic stresses in different plant species, possible through the regulation of the reactive oxygen species system [61, 62]. Transgenic Nicotiana benthamiana plants over-expressing GhWRKY39 had enhanced tolerance to salt and oxidative stress and increased expression of genes encoding antioxidant enzymes such as SOD, ascorbate peroxidase (APX), catalase (CAT) and glutathione-S-transferase (GST) [62]. Thus, leaf expression levels of antioxidant enzyme genes might be increased in response to B-deficiency. This agrees with our report that B-deficient citrus leaves had higher activities of SOD, APX, MDAR and GR [54]. Heat shock proteins (HSPs)/chaperones function in protecting plants against various stresses. As expected, the expression of miR6260 was down-regulated in B-deficient leaves accompanied by increased expression of its one target gene: chaperone DnaJ-domain superfamily protein (Table 2). Similarly, leaf expression levels of miR5929 and miR6214 were decreased by B-deficiency accompanied by increased expression levels of their corresponding target genes: DnaJ-domain superfamily protein (AT5G42480.1 and AT5G37380.4; Table 2). However, the expression of heat shock transcription factor A6B targeted by miR2099 were inhibited in B-deficient leaves despite down-regulated expression of miR2099 (Table 2). Hydroxyproline-rich glycoproteins (HRGPs) are the most abundant cell wall structural proteins in dicotyledonous plants [63]. Hall and Cannon demonstrated that the cell wall HRGP RSH was required for normal embryo development in
Arabidopsis [64]. Bonilla et al. observed that Bdeficiency-induced aberrant cell walls of bean root nodules lacked covalently bound HRGPs [65]. Here, the expression of HRGP family protein (AT2G25930.1), a target gene of miR3446, was up-regulated in B-deficient leaves (Table 2), thus enhancing plant tolerance to B-deficiency. However, miR3446 was down-regulated in B-deficient leaves, but its target gene (HRGP family protein; AT1G49330.1) was also depressed (Table 2).

B-deficiency lowered leaf expression level of miR158 (Table 2), as previously obtained on N-deficient Arabidopsis seedlings [27] and B-deficient citrus roots [8]. The downregulation of miR158 means that its target genes: SPFH/ Band 7/PHB domain-containing membrane-associated protein family, fucosyltransferase 2 and lipase class 3 family protein might be up-regulated in B-deficient leaves. However, qRT-PCR showed that the expression of the former two target genes was induced by B-deficiency, while the last one was down-regulated (Table 2). Lu et al. reported that fucosyltransferase 2 and lipase class 3 family protein were down-regulated in B-deficient citrus roots accompanied by decreased expression of miR158 [8].

The major facilitator superfamily (MFS) is the largest group of transport carriers, which are often coupled to the movement of another ion [66]. Kaya et al. reported that ATR1, which encodes a multidrug resistance transport protein of the MFS, was responsible for most of the tolerance of high B in Saccharomyces cerevisiae, concluding that ATR1 was a B exporter [67]. In this study, leaf $m i R 5037$ was induced by B-deficiency accompanied by decreased expression of its target gene: MFS protein (Table 2), thus decreasing B export from plants and improving plant tolerance to B-deficiency.

We found that leaf miR5266 was induced by Bdeficiency accompanied by increased expression of its target gene: ammonium transporter 1;1 (Table 2), which disagrees with our report that the abundance of miR5266 was lower in B-deficient citrus roots than in controls, while the expression level of ammonium transporter 1;1 was higher in the former [8].

We observed that miR3946 was inhibited in B-deficient leaves (Table 2), which disagrees with the previous report that miR3946 was induced in B-deficient C. sinensis roots [8]. All the 17 target genes targeted by miR3946 were induced by B-deficiency except for homeobox-leucine zipper protein $4(H B-4) / H D-Z I P$ protein, endosomal targeting BRO1-like domain-containing protein (AT1G13310.1), MYB domain protein 65 and SAUR-like auxin-responsive protein family (Table 2). Previous studies showed that B-deficiency increased the expression levels of some transport-related genes and the abundances of some transport-related proteins in citrus roots $[5,8]$, thus improving the tolerance of plants to B-deficiency. $B O R 1$, an efflux-type B transporter for xylem loading, 
play a key role in the tolerance of plants to low B. Arabidopsis bor1-1 mutant was more sensitive to Bdeficiency than the wild type [68]. Oryza sativa BOR1 has been demonstrated to be required for $\mathrm{B}$ acquisition by roots and translocation of $B$ into shoots [69]. Thus, B-deficiency-induced up-regulation of leaf endosomal targeting BRO1-like domain-containing protein (AT1G73390.1), phosphate transporter 1;7, MATE efflux family protein, vesicle-associated membrane protein 726 (targeted by miR3946), potassium transport 2/3 (targeted by miR3446), ammonium transporter 1;1 (targeted by miR5266), $\mathrm{Zn}$ transporter 10 precursor (targeted by miR5227) and cation $/ H^{+}$exchanger 25 (targeted by miR 2648) involved in cell transport (Table 2) might contribute to the tolerance of citrus to B-deficiency. HD-ZIP transcription factors are found only in plants. The expression of Hahb-4, a member of Helianthus annuus (sunflower) subfamily I, strongly increased in water-stressed sunflower [70]. Subsequent study showed transgenic Arabidopsis plants over-expressing Hahb-4 were more tolerant to drought by delaying the onset of senescence [71]. Huang et al. demonstrated that PtrbHLH, a basic helix-loop-helix transcription factor of Poncirus trifoliata might play a crucial role in cold tolerance via positively regulating peroxidase (POD)-mediated ROS scavenging [72]. Transketolase is a key enzyme of the pentose phosphate pathway (PPP) in plant cells. Our finding that transketolase was up-regulated in B-deficient leaves agrees with the report that transketolase activity in maize moderately increased in response to salt or oxidative stress [73]. In citrus, PPP has been suggested to play a role in the tolerance of plants to B-deficiency by providing reducing power (NADPH) and enhancing the antioxidant capacity [4]. Protein disulfide isomerases (PDIs), which act as molecular chaperones, play a role in the formation of proper disulfide bonds during protein folding [74]. Overexpression of a protein disulfide isomerase-like protein (PDIL) gene conferred $\mathrm{Hg}$ tolerance in transgenic plants, which had higher antioxidant capacity and lower levels of superoxide anion radicals, $\mathrm{H}_{2} \mathrm{O}_{2}$ and malondialdehyde (MDA) [75]. As shown in Table 2, the expression level of PDIL5-3 targeted by miR3946 was increased in B-deficient leaves. To conclude, down-regulation of miR3946 in Bdeficient leaves might be an adaptive response of plants to B-deficiency.

Carotenoid (Car) isomerase (CRTISO), which catalyzes the isomerization of poly-cis-carotenoids to all trans-carotenoids in higher plants, is a regulatory step for Car biosynthesis. Arabidopsis mutants of crtiso had increased accumulation of poly-cis-carotenoids and reduced lutein concentration [76, 77]. Here, the expression of miR6025 was increased and its one target gene: CRTISO was decreased in B-deficient leaves (Table 2), thus impairing Car biosynthesis. This agrees with our report that B- deficient citrus leaves had lower Car concentration [54]. Plant phenolic secondary metabolites and their precursors are synthesized via the pathway of shikimate biosynthesis [78]. Shikimate kinase, a key enzyme for the biosynthesis of polyphenols, catalyzes the fifth reaction of the shikimate pathway. As shown in Table 2, the expression level of shikimate kinase 1 was down-regulated in B-deficient leaves and the expression of miR6025, which targets the gene, was up-regulated. This disagrees with our report that B-deficient citrus leaves displayed increased accumulation of phenolics [4].

Mitogen-activated protein kinase (MAPK) cascades play important roles in plant response to various stresses. Each MAPK cascade consists of MAPKs, MAPK kinases (MAPKKs), and MAPKK kinases (MAPKKKs). In plants, MAPKKKs have been shown to be involved in various stresses. Ning et al. showed that transgenic rice plants over-expressing DSM1 (a putative MAPKKK gene in rice) displayed higher tolerance to dehydration at the seedling stage by regulating ROS scavenging [79]. In this study, leaf transcript of miR3446 was decreased by B-deficiency and its target gene (MAPKKK5) was up-regulated under Bdeficiency. This agrees with the report that MAPKKK genes were induced by drought, heat, salt, cold, IAA and jasmonic acid (JA) in Arabidopsis [80].

Our finding that leaf expression level of miR7539 decreased in response to B-deficiency, and its target gene (phosphoenolpyruvate carboxylase, PEPC) was induced by B-deficiency (Table 2). This agrees with our report that B-deficient citrus leaves had increased activity of PEPC and dark respiration [4].

\section{Conclusion}

We identified 734 known and 71 novel miRNAs from B-sufficient and -deficient citrus leaves using Illumina sequencing, and obtained 91 (83 known and 8 novel) up- and 81 (75 known and 6 novel) down-regulated miRNAs from B-deficient citrus leaves. Obviously, the expression of miRNAs was greatly altered in B-deficient leaves, which might play a role in the tolerance of plants to B-deficiency. In this study, we proposed a model for the responses of leaf miRNAs to B-deficiency by integrating the present results with the data available in the previous literatures (Fig. 4). The adaptive responses of leaf miRNAs to B-deficiency might be associated with several aspects: (a) attenuation of plant growth and development by down-regulating TIR1, $A R F$ and $A F B$ due to up-regulated miR393 and miR160, and by lowering the expression of SAUR-like auxin-responsive protein family targeted by miR3946, thus enhancing plant stress tolerance; $(b)$ improving the expression of NACs due to decreased expression miR159, miR782, miR3946 and miR7539, hence maintaining leaf phenotype and enhancing the 


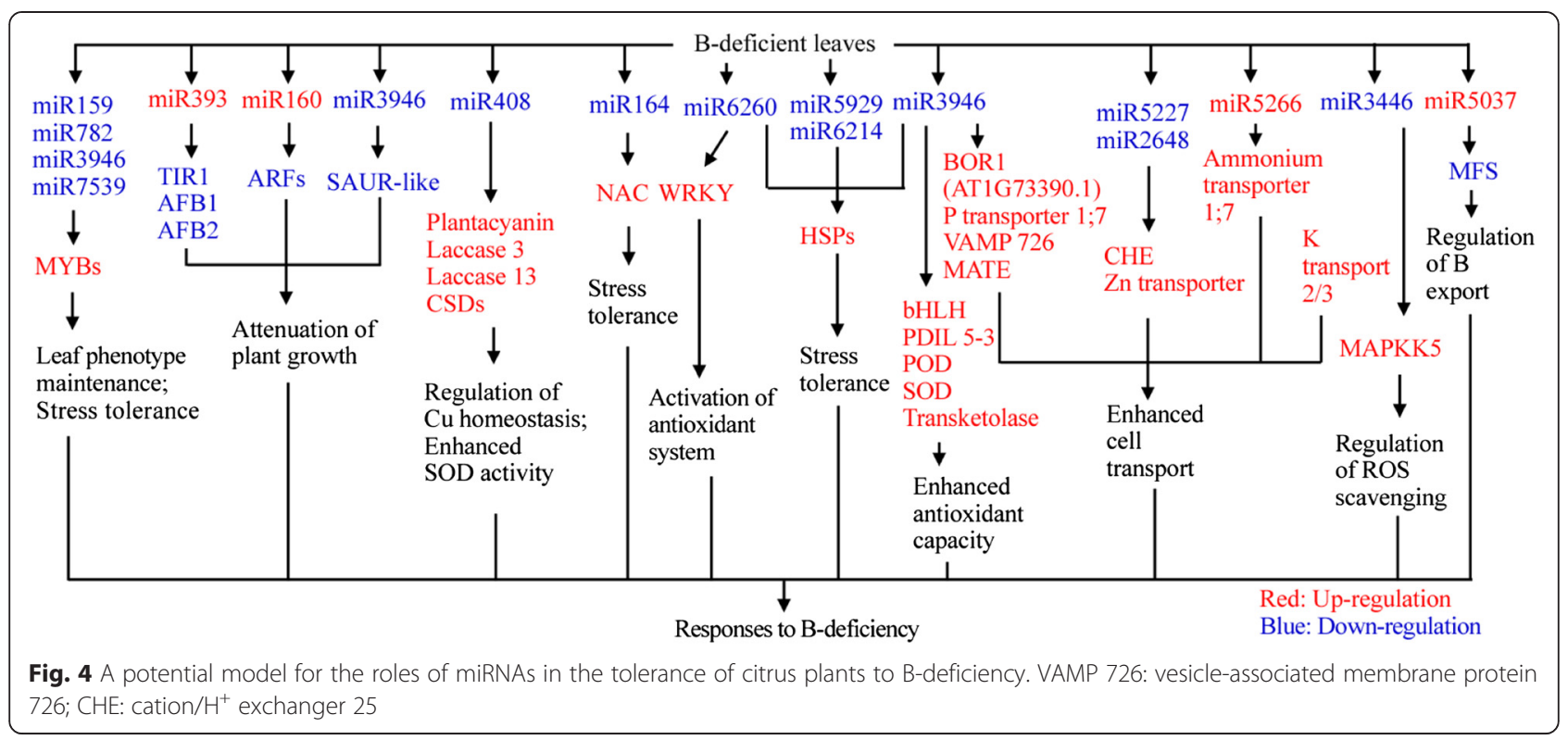

stress tolerance; $(c)$ activation of the stress responses and antioxidant system due to decreased expression of miR164, miR6260, miR5929, miR6214, miR3946 and miR3446; $(d)$ decreased expression of MFS resulting from increased expression of miR5037, thus lowering B export from plants. In addition, B-deficiency-induced down-regulation of miR408 might be involved in the tolerance of plants to B-deficiency by regulating $\mathrm{Cu}$ homeostasis and enhancing SOD activity. In conclusion, our study reveals some adaptive mechanisms of citrus to B-deficiency.

\section{Methods}

Plant culture and B treatments

Both plant culture and B treatments were performed according to Yang et al. [5] and Lu et al. [8]. Briefly, 15-week-old seedlings of 'Xuegan' [Citrus sinensis (L.) Osbeck] grown in $6 \mathrm{~L}$ pots (two seedlings per pot) containing fine river sand were supplied every other day until dripping with B-deficient $\left(0 \mu \mathrm{M} \mathrm{H}_{3} \mathrm{BO}_{3}\right)$ or -sufficient $\left(10 \mu \mathrm{M} \quad \mathrm{H}_{3} \mathrm{BO}_{3}\right)$ nutrient solution for 15 weeks. There were 10 replications per $\mathrm{B}$ treatment with 2 pots in a completely randomized design. At the end of the experiment, fully-expanded leaves from different replicates and treatments were collected at noon under full sun and frozen immediately in liquid $\mathrm{N}_{2}$. Leaf samples were stored at $-80{ }^{\circ} \mathrm{C}$ until extraction. It's worth mentioning that $C$. sinensis is polyembryonic seed development, an apomictic process in which many embryos are initiated directly from the maternal nucellar cells surrounding the embryo sac containing a developing zygotic embryo [81].

\section{Isolation of leaf sRNAs, library construction and Illumina} sequencing

About $0.1 \mathrm{~g}$ mixed frozen B-sufficient and -deficient leaves from five replications were used to extract RNA. Total RNA was extracted from frozen leaves using TRIzol reagent (Invitrogen, Carlsbad, CA) following manufacturer's instructions. Two sRNA libraries were constructed according to Lu et al. [8]. High throughput sequencing was performed on a Solexa sequencer (Illumina) at the Beijing Genomics Institute (BGI), Shenzhen, China.

\section{sRNA annotation and miRNA identification}

Both sRNA annotation and miRNA identification were performed according to $\mathrm{Lu}$ et al. [8]. Briefly, software developed by the BGI was used to deal with the raw data from the Solexa sequencing. Clean reads were then used to analyze length distribution and common/specific sequences. Thereafter, the clear reads were mapped to $C$. sinensis genome (JGIversion 1.1, http://phytozome.jgi.doe.gov/pz/portal.html\#!info?alias=Org_Csinensis) using SOAP, only perfectly mapped sequences were retained and analyzed further. rRNAs, tRNAs, snRNAs and snoRNAs were removed from the sRNAs sequences through BLASTn search using NCBI Genebank database (http:// www.ncbi.nlm.nih.gov/blast/Blast.cgi/) and Rfam (12.0) database (http://www.sanger.ac.uk/resources/databases/ rfam.html $)(e=0.01)$. The remaining sequences were aligned with known plant miRNAs from miRBase 21 (http://www.mirbase.org/). Only the perfectly matched sequences were considered to be conserved miRNAs. Reads that were not annotated were used to predict novel miRNAs using a prediction software Mireap (http:// 
sourceforge.net/projects/mireap/), which was developed by the BGI, by exploring the secondary structure, the Dicer cleavage site and the minimum free energy of the unannotated small RNA tags which could be mapped to genome. In addition, we used MTide: an integrated tool for the identification of miRNA-target interaction in plants (http://bis.zju.edu.cn/MTide) [82] and DNAMAN 8 (http:// www.lynnon.com/pc/framepc.html) to predict novel miR NA. Only these miRNA candidates that were simultaneously predicted by the three softwares were considered to be real novel miRNAs.

\section{Differential expression analysis of miRNAs}

Both the fold change between B-deficiency and -sufficiency and the $P$-value were calculated from the normalized expression of TPM [83]. A $1.5 \log 2$-fold cut-off was set to determine up- and down-regulated miRNAs in addition to a $P$-value of less than 0.01 [8].

\section{Target prediction of miRNAs}

This was performed by RNAhybrid based on rules suggested by Allen et al. [84] and Schwab et al. [85].

\section{Functions of the potential targets of the differentially expressed miRNAs}

All targets of the differentially expressed miRNAs were mapped to GO terms in the database (http://www.geneontology.org/), and calculated gene numbers for each term. The GO results were expressed as three categories: cellular component, molecular function, biological process [8].

\section{Validation of miRNA expression by stem-loop qRT-PCR}

The detection of miRNA expression was performed using stem-loop qRT-PCR method, stem-loop primers for reverse transcription and primers for qRT-PCR were listed in Additional file 8. Total RNA was reversetranscribed using Taqman $^{\circ}$ MicroRNA Reverse Transcription Kit (USA), and SYBR ${ }^{\circ}$ Premix Ex Taq ${ }^{\text {TI }}$ II (Takara, Japan) kit was used for qRT-PCR. MiRNA special (forward) primers were designed according to the miRNA sequence but excluded the last six nucleotides at 3' end of the miRNA. A 5' extension of several nucleotides, which was chosen randomly and relatively GC-rich, was added to each forward primer to increase the melting temperature [86]. All the primers were assigned to Primer Software Version 5.0 (PREMIER Biosoft International, USA) to assess their quality. For qRT-PCR, $20 \mu \mathrm{L}$ reaction solution contained $10 \mu \mathrm{L}$ ready-to-use SYBR $^{\circ}$ Premix Ex TaqTM II (Takara, Japan), $0.8 \mu \mathrm{L}$ $10 \mu \mathrm{M}$ miRNA forward primer, $0.8 \mu \mathrm{L} 10 \mu \mathrm{M}$ Uni-miR qPCR primer, $2 \mu \mathrm{L}$ cDNA template and $6.4 \mu \mathrm{L} \mathrm{dH}_{2} \mathrm{O}$. The cycling conditions were $60 \mathrm{~s}$ at $95{ }^{\circ} \mathrm{C}$, followed by 40 cycles of $95{ }^{\circ} \mathrm{C}$ for $10 \mathrm{~s}, 60{ }^{\circ} \mathrm{C}$ for $30 \mathrm{~s}$. qRT-PCR was performed on the ABI 7500 Real Time System. Samples for qRT-PCR were run in at least three biological replicates with two technical replicates. Relative miRNA expression was calculated using ddCt algorithm. For the normalization of miRNA expression, actin (AEK97331.1) was used as an internal standard and the leaves from control plants were used as reference sample, which was set to 1 .

\section{qRT-PCR analysis of miRNA target gene expression}

Total RNA was extracted from frozen B-sufficient and -deficient leaves using TRIzol reagent (Invitrogen, Carlsbad, CA) following manufacturer's instructions. The sequences of the F and R primers used were given in Additional file 9. qRT-PCR analysis of miRNA target gene expression was performed using a ABI 7500 Real Time System according to Lu et al. [8].

\section{Experimental design and statistical analysis}

There were 20 pot seedlings per treatment in a completely randomized design. Experiments were performed with 3 replicates. Differences among treatments were separated by the least significant difference (LSD) test at $P<0.05$ level.

\section{Availability of data and materials}

"The data set supporting the results of this article are available in the Gene Expression Omnibus repository under accession no GSE72108 (http://www.ncbi.nlm.nih.gov/geo/query/acc.cgi?acc=GSE72108)". The mature miRNA and precursor sequences will be submitted to miRBase registry and assigned final names after final acceptance of the manuscript.

\section{Additional files}

Additional file 1: Length distribution of small RNAs from control
and B-deficient leaves of Citrus sinensis seedlings. (DOC $81 \mathrm{~kb}$ )
Additional file 2: List of known miRNAs in Citrus sinensis leaves.
(DOC $1525 \mathrm{~kb}$ )
Additional file 3: List of known miRNAs in Citrus sinensis leaves
after removing these miRNAs with normalized read-count less than
10 TPM in the two miRNA libraries constructed from control and
B-deficient leaves. (DOC $452 \mathrm{~kb}$ )
Additional file 4: List of novel miRNAs in Citrus sinensis leaves.
(DOC $158 \mathrm{~kb}$ )
Additional file 5: List of novel miRNAs in Citrus sinensis leaves after
removing these miRNAs with normalized read-count less than 10
TPM in two miRNA libraries constructed from control and B-
deficient leaves. (DOC $69 \mathrm{~kb})$
Additional file 6: List of target genes for parts of known miRNAs in
Citrus sinensis leaves. (DOC $198 \mathrm{~kb}$ )
Additional file 7: List of target genes for parts of novel miRNAs in
Citrus sinensis leaves. (DOC $33 \mathrm{~kb}$ )
Additional file 8: List of stem loop qRT-PCR primers. (DOC $61 \mathrm{~kb}$ )
Additional file 9: Specific primer pairs used for qRT-PCR expression
analysis of selected miRNA target genes. (DOC $160 \mathrm{~kb}$ )




\section{Competing interests}

The authors declare that they have no competing interests.

\section{Authors' contributions}

YBL carried out most of the experiments and drafted the manuscript; YPQ participated in the design of the study. LTY participated in the design of the study and coordination; PG participated in data analysis; YL directed the study; LSC designed and directed the study and revised the manuscript.

\section{Acknowledgments}

This study was jointly supported by the National Natural Science Foundation of China (No. 31171947) and the earmarked fund for China Agriculture Research System (No. CARS-27).

\section{Author details}

${ }^{1}$ College of Resource and Environmental Science, Fujian Agriculture and Forestry University, Fuzhou 350002, China. ${ }^{2}$ Institute of Horticultural Plant Physiology, Biochemistry and Molecular Biology, Fujian Agriculture and Forestry University, Fuzhou 350002, China. ${ }^{3}$ Institute of Materia Medica, Fujian Academy of Medical Sciences, Fuzhou 350001, China. ${ }^{4}$ The Higher Educational Key Laboratory of Fujian Province for Soil Ecosystem Health and Regulation, Fujian Agriculture and Forestry University, Fuzhou 350002, China. ${ }^{5}$ Fujian Key Laboratory for Plant Molecular and Cell Biology, Fujian Agriculture and Forestry University, Fuzhou 350002, China.

\section{Received: 6 June 2015 Accepted: 8 October 2015}

\section{Published online: 04 November 2015}

\section{References}

1. Cakmak I, Römheld V. Boron deficiency-induced impairments of cellular functions in plants. Plant Soil. 1997;193:71-83.

2. Dell B, Huang L. Physiological response of plants to low boron. Plant Soil. 1997;193:103-20

3. Chen LS, Han S, Qi YP, Yang LT. Boron stresses and tolerance in citrus. Afr J Biotech. 2012;11:5961-9.

4. Lu YB, Yang LT, Li Y, Xu J, Liao TT, Chen YB, et al. Effects of boron deficiency on major metabolites, key enzymes and gas exchange in leaves and roots of Citrus sinensis seedlings. Tree Physiol. 2014;34:608-18.

5. Yang LT, Qi YP, Lu YB, Guo P, Sang W, Feng H, et al. iTRAQ protein profile analysis of Citrus sinensis roots in response to long-term boron-deficiency. J Proteomics. 2013;93:179-206.

6. Huang YZ, Li J, Wu SH, Pang DM. Nutrition condition of the orchards in the main production areas of Guanxihoney pomelo trees (Pinhe county). J Fujian Agri Univ. 2001;30:40-3.

7. Jones-Rhoades MW, Bartel DP, Bartel B. MicroRNAs and their regulatory roles in plants. Annu Rev Plant Biol. 2006;57:19-53.

8. Lu YB, Yang LT, Qi YP, Li Y, Li Z, Chen YB, et al. Identification of boron-deficiencyresponsive microRNAs in Citrus sinensis roots by Illumina sequencing. BMC Plant Biol. 2014;14:123.

9. Paul S, Datta SK, Datta K. MiRNA regulation of nutrient homeostasis in plants. Front Plant Sci. 2015;6:232

10. Zeng $H$, Wang $G$, Hu $X$, Wang $H$, Du L, Zhu Y. Role of microRNAs in plant responses to nutrient stress. Plant Soil. 2014;374:1005-21.

11. Chiou TJ, Lin SI. Signaling network in sensing phosphate availability in plants. Annu Rev Plant Biol. 2011;62:185-206.

12. Xu F, Liu Q, Chen L, Kuang J, Walk T, Wang J, et al. Genome-wide identification of soybean microRNAs and their targets reveals their organ-specificity and responses to phosphate starvation. BMC Genomics. 2013;14:66.

13. Hsieh LC, Lin SI, Shih ACC, Chen JW, Lin WY, Tseng CY, et al. Uncovering small RNA-mediated responses to phosphate deficiency in Arabidopsis by deep sequencing. Plant Physiol. 2009;151:2120-32.

14. Shukla LI, Chinnusamy V, Sunkar R. The role of microRNAs and other endogenous small RNAs in plant stress responses. Biochim Biophys Acta. 1779;2008:743-8

15. Hackenberg M, Huang PJ, Huang CY, Shi BJ, Gustafson P, Langridge P. A comprehensive expression profile of microRNAs and other classes of noncoding small RNAs in barley under phosphorous-deficient and -sufficient conditions. DNA Res. 2013;20:109-25.

16. Zhu YY, Zeng HQ, Dong CX, Yin XM, Shen QR, Yang ZM. MicroRNA expression profiles associated with phosphorus deficiency in white lupin (Lupinus albus L.). Plant Sci. 2010;178:23-9.
17. Valdés-López O, Yang SS, Aparicio-Fabre R, Graham PH, Reyes JL, Vance CP, et al. MicroRNA expression profile in common bean (Phaseolus vulgaris) under nutrient deficiency stresses and manganese toxicity. New Phytol. 2010;187:805-18.

18. Pant BD, Musialak-Lange M, Nuc P, May P, Buhtz A, Kehr J, et al. Identification of nutrient responsive Arabidopsis and rapeseed microRNAs by comprehensive real-time polymerase chain reaction profiling and small RNA sequencing. Plant Physiol. 2009;150:1541-55.

19. Gu M, Xu K, Chen AQ, Zhu YY, Tang GL, Xu GH. Expression analysis suggests potential roles of microRNAs for phosphate and arbuscular mycorrhizal signaling in Solanum lycopersicum. Physiol Plant. 2010;138:226-37.

20. Pei $L$, Jin Z, Li K, Yin H, Wang J, Yang A. Identification and comparative analysis of low phosphate tolerance associated microRNAs in two maize genotypes. Plant Physiol Biochem. 2013;70:221-34.

21. Zhao X, Liu X, Guo C, Gu J, Xiao K. Identification and characterization of microRNAs from wheat (Triticum aestivum L.) under phosphorus deprivation. J Plant Biochem Biotechnol. 2013;22:113-23.

22. Abdel-Ghany SE, Pilon M. MicroRNA-mediated systemic down-regulation of copper protein expression in response to low copper availability in Arabidopsis. J Biol Chem. 2008;283:15932-45.

23. Yamasaki H, Abdel-Ghany SE, Cohu CM, Kobayashi Y, Shikanai T, Pilon M. Regulation of copper homeostasis by microRNA in Arabidopsis. J Biol Chem. 2007;282:16369-78.

24. Liang G, Yang F, Yu D. MicroRNA395 mediates regulation of sulfate accumulation and allocation in Arabidopsis thaliana. Plant J. 2010;62:1046-57.

25. Kong WW, Yang ZM. Identification of iron-deficiency responsive microRNA genes and cis-elements in Arabidopsis. Plant Physiol Biochem. 2010;48:153-9.

26. Waters BM, McInturf SA, Stein RJ. Rosette iron deficiency transcript and microRNA profiling reveals links between copper and iron homeostasis in Arabidopsis thaliana. J Exp Bot. 2012;63:5903-18.

27. Liang $\mathrm{G}, \mathrm{He} H, \mathrm{Yu}$ D. Identification of nitrogen starvation-responsive microRNAs in Arabidopsis thaliana. PLoS One. 2012;7:e48951.

28. Xu Z, Zhong S, Li X, Li W, Rothstein SJ, Zhang S, et al. Genome-wide identification of microRNAs in response to low nitrate availability in maize leaves and roots. PLoS One. 2011;6:e28009.

29. Zhao M, Ding H, Zhu JK, Zhang F, Li WX. Involvement of miR169 in the nitrogen-starvation responses in Arabidopsis. New Phytol. 2011;190:906-15.

30. Lu Y, Qi Y, Lee J, Guo P, Ye X, Jia M, et al. Long-term boron-deficiencyresponsive genes revealed by cDNA-AFLP differ between Citrus sinensis roots and leaves. Front Plant Sci. 2015;6:585.

31. Chapman HD. The mineral nutrition of citrus. In: Reuther W, Webber HJ, Batchelor LD, editors. The citrus industry, volume 2. CA: Division of Agricultural Sciences, University of California; 1968. p. 127-89.

32. Li R, Li Y, Kristiansen K, Wang J. SOAP: short oligonucleotide alignment program. Bioinformatics. 2008;24:713-4.

33. Xu Q, Liu Y, Zhu A, Wu X, Ye J, Yu K, et al. Discovery and comparative and comparative profiling of microRNAs in a sweet orange red-flesh mutant and its wild type. BMC Genomics. 2010;11:246.

34. Song C, Wang C, Zhang C, Korir NK, Yu H, Ma Z, et al. Deep sequencing discovery of novel and conserved microRNAs in trifoliate orange (Citrus trifoliata). BMC Genomics. 2010;11:431

35. Chen L, Wang T, Zhao M, Tian Q, Zhang WH. Identification of aluminumresponsive microRNAs in Medicago truncatula by genome-wide highthroughput sequencing. Planta. 2012;235:375-86.

36. Meyers BC, Axtell MJ, Bartel B, Bartel DP, Baulcombe D, Bowman JL, et al. Criteria for annotation of plant microRNAs. Plant Cell. 2008;20:3186-90.

37. Zhao M, Tai H, Sun S, Zhang F, Xu Y, Li WX. Cloning and characterization of maize miRNAs involved in responses to nitrogen deficiency. PLoS One. 2012;7:e29669.

38. Patade $W$, Suprasanna P. Short-term salt and PEG stresses regulate expression of microRNA, miR159 in sugarcane leaves. J Crop Sci Biotech. 2010;13:177-82.

39. Zeng HQ, Zhu YY, Huang SQ, Yang ZM. Analysis of phosphorus-deficient responsive miRNAs and cis-elements from soybean (Glycine max L.). J Plant Physiol. 2010;167:1289-97.

40. Palatnik J, Allen E, Wu X, Schommer C, Schwab R, Carrington J, et al. Control of leaf morphogenesis by microRNAs. Nature. 2003:425:257-63.

41. Dai $X, X u Y, M a Q, X u$ W, Wang $T$, Xue $Y$, et al. Overexpression of an R1R2R3 MYB gene, OsMYB3R-2, increases tolerance to freezing, drought, and salt stress in transgenic Arabidopsis. Plant Physiol. 2007;143:1739-51.

42. Wimmer MA, Eichert T. Review: mechanisms for boron deficiency-mediated changes in plant water relations. Plant Sci. 2013;203-204:25-32. 
43. Yang CQ, Liu YZ, An JC, Li S, Jin LF, Zhou GF, et al. Digital gene expression analysis of corky split vein caused by boron deficiency in 'Newhall' navel orange (Citrus sinensis Osbeck) for selecting differentially expressed genes related to vascular hypertrophy. PLoS One. 2013;8:e65737.

44. Si-Ammour A, Windels D, Arn-Bouldoires E, Kutter C, Ailhas J, Meins Jr F, et al. MiR393 and secondary siRNAs regulate expression of the TIR1/AFB2 auxin receptor clade and auxin-related development of Arabidopsis leaves. Plant Physiol. 2010;157:683-91.

45. Windels D, Vazquez F. MiR393: integrator of environmental cues in auxin signaling? Plant Signal Behav. 2011;6:1672-75.

46. Chapman EJ, Estelle M. Mechanism of auxin-regulated gene expression in plants. Annu Rev Genet. 2009;43:265-85.

47. Sunkar R, Li YF, Jagadeeswaran G. Functions of microRNAs in plant stress. Trends Plant Sci. 2012;17:196-203.

48. Mallory AC, Bartel DP, Bartel B. MicroRNA-directed regulation of Arabidopsis AUXIN RESPONSE FACTOR17 is essential for proper development and modulates expression of early auxin response genes. Plant Cell. 2005;17:1360-75.

49. Phookaew P, Netrphan S, Sojikul P, Narangajavana J. Involvement of miR164- and miR167-mediated target gene expressions in responses to water deficit in cassava. Biol Plant. 2014:58:469-78.

50. Hu H, Dai M, Yao J, Xiao B, Li X, Zhang Q, et al. Overexpressing a NAM, ATAF, and CUC (NAC) transcription factor enhances drought resistance and salt tolerance in rice. Proc Natl Acad Sci U S A. 2006;103:12987-92.

51. Nakashima K, Tran LS, Nguyen DV, Fujita M, Maruyama K, Todaka D, et al. Functional analysis of a NAC-type transcription factor OsNAC6 involved in abiotic and biotic stress responsive gene expression in rice. Plant J. 2007:51:617-30

52. Zhu M, Chen G, Zhang J, Zhang Y, Xie Q, Zhao Z, et al. The abiotic stressresponsive NAC-type transcription factor SINAC4 regulates salt and drought tolerance and stress-related genes in tomato (Solanum lycopersicum). Plant Cell Rep. 2014;33:1851-63.

53. Zhuang YM. Citrus nutrition and fertilizeration. Beijing: China Agriculture Press; 1994.

54. Han S, Chen LS, Jiang HX, Smith BR, Yang LT, Xie CY. Boron deficiency decreases growth and photosynthesis, and increases starch and hexoses in leaves of citrus seedlings. J Plant Physiol. 2008;165:1331-41.

55. Redondo-Nieto M, Maunoury $\mathrm{N}$, Mergaert $\mathrm{P}$, Kondorosi E, Bonilla I, Bolaños $\mathrm{L}$. Boron and calcium induce major changes in gene expression during legume nodule organogenesis. Does boron have a role in signalling? New Phytol. 2012;195:14-9.

56. Zhou J, Liu M, Jiang J, Qiao G, Lin S, Li H, et al. Expression profile of miRNAs in Populus cathayana L. and Salix matsudana Koidz under salt stress. Mol Biol Rep. 2012;39:8645-54.

57. Bolle $C$. The role of GRAS proteins in plant sigal transduction and development. Planta. 2004;218:683-92.

58. Rhoades MW, Reinhart BJ, Lim LP, Burge CB, Bartel B, Bartel DP. Prediction of plant microRNA targets. Cell. 2002;110:513-20.

59. Pan $L J$, Jiang $L$. Identification and expression of the WRKY transcription factors of Carica papaya in response to abiotic and biotic stresses. Mol Biol Rep. 2014;41:1215-25.

60. Kasajima I, Ide Y, Yokota Hirai M, Fujiwara T. WRKY6 is involved in the response to boron deficiency in Arabidopsis thaliana. Physiol Plant. 2010;139:80-92.

61. Liu QL, Xu KD, Pan YZ, Jiang BB, Liu GL, Jia Y, et al. Functional analysis of a novel chrysanthemum WRKY transcription factor gene involved in salt tolerance. Plant Mol Biol Rep. 2014;32:282-9.

62. Shi W, Liu D, Hao L, Wu C, Guo X, Li H. GhWRKY39, a member of the WRKY transcription factor family in cotton, has a positive role in disease resistance and salt stress tolerance. Plant Cell Tiss Org. 2014;118:17-32.

63. Sommer-Knudsen J, Bacic A, Clarke AE. Hydroxyproline-rich plant glycoproteins. Phytochemistry. 1997;47:483-97.

64. Hall Q, Cannon MC. The cell wall hydroxyproline-rich glycoprotein RSH is essential for normal embryo development in Arabidopsis. Plant Cell. 2002;14:1161-72.

65. Bonilla I, Mergold-Villaseñor C, Campos ME, Sánchez N, Pérez H, López L, et al. The aberrant cell walls of boron-deficient bean root nodules have no covalently bound hydroxyproline-/proline-rich proteins. Plant Physiol. 1997;115:1329-40.

66. Lin SI, Santi C, Jobet E, Lacut E, El Kholti N, Karlowski WM, et al. Complex regulation of two target genes encoding SPX-MFS proteins by rice miR827 in response to phosphate starvation. Plant Cell Physiol. 2010;51:2119-31.
67. Kaya A, Karakaya HC, Fomenko DE, Gladyshev VN, Koc A. Identification of a novel system for boron transport: Atr1 is a main boron exporter in yeast. Mol Cell Biol. 2009;29:3665-74.

68. Takano J, Noguchi K, Yasumori M, Kobayashi M, Gajdos Z, Miwa K, et al. Arabidopsis boron transporter for xylem loading. Nature. 2002;420:337-40.

69. Nakagawa Y, Hanaoka H, Kobayashi M, Miyoshi K, Miwa K, Fujiwara T. Cell-type specificity of the expression of Os BOR1, a rice efflux boron transporter gene, is regulated in response to boron availability for efficient boron uptake and xylem loading. Plant Cell. 2007;19:2624-35.

70. Gago GM, Almoguera C, Jordano J, Gonzalez DH, Chan RL. Hahb-4, a homeobox-leucine zipper gene potentially involved in abscisic acid-dependent responses to water stress in sunflower. Plant Cell Environ. 2002;25:633-40.

71. Dezar CA, Gago GM, Gonzalez DH, Chan RL. Hahb-4, a sunflower homeobox-leucine zipper gene, is a developmental regulator and confers drought tolerance to Arabidopsis thaliana plants. Transgenic Res. 2005;14:429-40.

72. Huang XS, Wang W, Zhang Q, Liu JH. A basic helix-loop-helix transcription factor, PtrbHLH, of Poncirus trifoliata confers cold tolerance and modulates peroxidasemediated scavenging of hydrogen peroxide. Plant Physiol. 2013;162:1178-94.

73. Rapala-Kozik M, Kowalska E, Ostrowska K. Modulation of thiamine metabolism in Zea mays seedlings under conditions of abiotic stress. J Exp Bot. 2008;59:4133-43.

74. Houston NL, Fan C, Xiang JQ, Schulze JM, Jung R, Boston RS. Phylogenetic analyses identify 10 classes of the protein disulfide isomerase family in plants, including single-domain protein disulfide isomerase-related proteins. Plant Physiol. 2005;137:762-78.

75. Chen Z, Pan Y, Wang S, Ding Y, Yang W, Zhu C. Overexpression of a protein disulfide isomerase-like protein from Methanothermobacter thermoautotrophicum enhances mercury tolerance in transgenic rice. Plant Sci. 2012;197:10-20.

76. Cazzonelli Cl, Roberts AC, Carmody ME, Pogson BJ. Transcriptional control of SET DOMAIN GROUP 8 and CAROTENOID ISOMERASE during Arabidopsis development. Mol Plant. 2010;3:174-91.

77. Wei J, Xu M, Zhang D, Mi H. The role of carotenoid isomerase in maintenance of photosynthetic oxygen evolution in rice plant. Acta Biochim Biophys Sin. 2010;42:457-63.

78. Tohge T, Watanabe M, Hoefgen R, Fernie AR. The evolution of phenylpropanoid metabolism in the green lineage. Crit Rev Biochem Mol Biol. 2013;48:123-52.

79. Ning J, Li X, Hicks LM, Xiong L. A Raf-like MAPKKK gene DSM1 mediates drought resistance through reactive oxygen species scavenging in rice. Plant Physiol. 2010;152:876-90.

80. Wu J, Wang J, Pan C, Guan X, Wang Y, Liu S, et al. Genome-wide identification of MAPKK and MAPKKK gene families in tomato and transcriptional profiling analysis during development and stress response. PLoS One. 2014;9:e103032.

81. Aleza P, Juárez J, Ollitrault P, Navarro L. Polyembryony in non-apomictic citrus genotypes. Ann Bot. 2010;106:533-45.

82. Zhang Z, Jiang L, Wang J, Gu P, Chen M. MTide: an integrated tool for the identification of miRNA-target interaction in plants. Bioinformatics. 2015;31(2):290-1.

83. Wang T, Chen L, Zhao M, Tian Q, Zhang WH. Identification of drought-responsive microRNAs in Medicago truncatula by genome-wide high throughout sequencing BMC Genomics. 2011;12:367.

84. Allen E, Xie Z, Gustafson AM, Carrington JC. MicroRNA-directed phasing during trans-acting siRNA biogenesis in plants. Cell. 2005;121:207-21.

85. Schwab R, Palatnik JF, Riester M, Schommer C, Schmid M, Weigel D. Specific effects of microRNAs on the plant transcriptome. Dev Cell. 2005;8:517-27.

86. Chen C, Ridzon DA, Broomer AJ, Zhou Z, Lee DH, Nguyen JT, et al. Real-time quantification of microRNAs by stem-loop RT-PCR. Nucleic Acids Res. 2005:33:e179. 